\title{
Boswellic acids/Boswellia serrata extract as a potential COVID-19 therapeutic agent in the elderly
}

\author{
Adel A. Gomaa ${ }^{1}$ (D) Hamdy S. Mohamed ${ }^{3} \cdot$ Rasha Bakheet Abd-ellatief $^{1} \cdot$ Mohamed A. Gomaa $^{2}$
}

Received: 30 March 2021 / Accepted: 20 June 2021 / Published online: 5 July 2021

(c) The Author(s), under exclusive licence to Springer Nature Switzerland AG 2021

\begin{abstract}
The most severe cases of COVID-19, and the highest rates of death, are among the elderly. There is an urgent need to search for an agent to treat the disease and control its progression. Boswellia serrata is traditionally used to treat chronic inflammatory diseases of the lung. This review aims to highlight currently published research that has shown evidence of potential therapeutic effects of boswellic acids (BA) and B. serrata extract against COVID-19 and associated conditions. We reviewed the published information up to March 2021. Studies were collected through a search of online electronic databases (academic libraries such as PubMed, Scopus, Web of Science, and Egyptian Knowledge Bank). Several recent studies reported that BAs and B. serrata extract are safe agents and have multiple beneficial activities in treating similar symptoms experienced by patients with COVID-19. Because of the low oral bioavailability and improvement of buccal/oral cavity hygiene, traditional use by chewing B. serrata gum may be more beneficial than oral use. It is the cheapest option for a lot of poorer people. The promising effect of $B$. serrata and BA can be attributed to its antioxidant, anti-inflammatory, immunomodulatory, cardioprotective, anti-platelet aggregation, antibacterial, antifungal, and broad antiviral activity. B. serrata and BA act by multiple mechanisms. The most common mechanism may be through direct interaction with IкB kinases and inhibiting nuclear factor- $\mathrm{\kappa B}-$ regulated gene expression. However, the most recent mechanism proposed that BA not only inhibited the formation of classical 5-lipoxygenase products but also produced anti-inflammatory LOX-isoform-selective modulators. In conclusion a small to moderate dose $B$. serrata extract may be useful in the enhancing adaptive immune response in mild to moderate symptoms of COVID-19. However, large doses of BA may be beneficial in suppressing uncontrolled activation of the innate immune response. More clinical results are required to determine with certainty whether there is sufficient evidence of the benefits against COVID-19.
\end{abstract}

Keywords Boswellic acids/Boswellia serrata $\cdot$ Antioxidant $\cdot$ anti-inflammatory $\cdot$ Antiviral immunomodulator $\cdot$ COVID-19

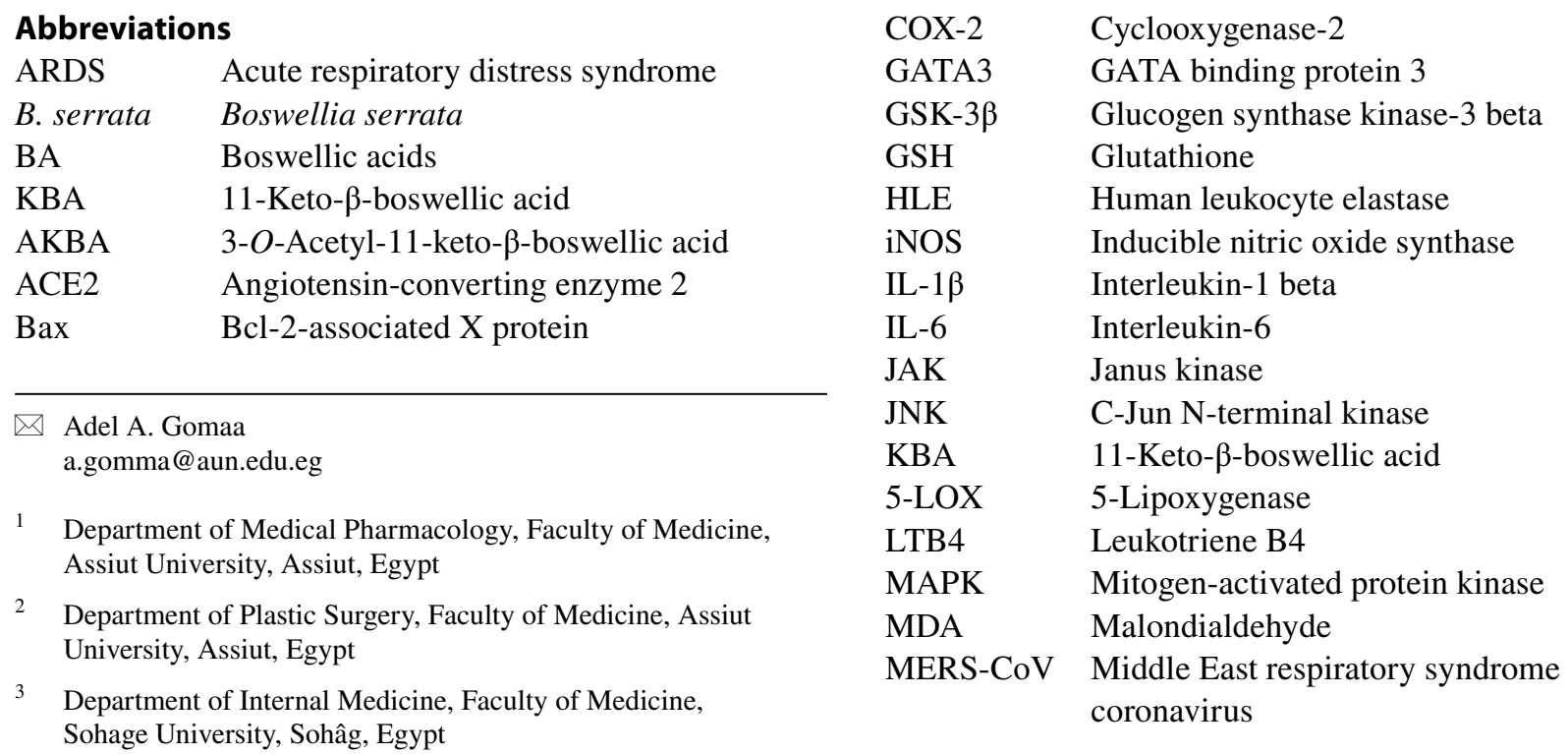




\begin{tabular}{|c|c|}
\hline$N F-\kappa B$ & Nuclear factor kappa B \\
\hline SASP & Senescence-associated secretory phenotype \\
\hline SARS-CoV & $\begin{array}{l}\text { Severe acute respiratory syndrome } \\
\text { coronavirus }\end{array}$ \\
\hline STAT & $\begin{array}{l}\text { Signal transducer and activator of } \\
\text { transcription }\end{array}$ \\
\hline SOD & Superoxide dismutase \\
\hline TNF $\alpha$ & Tumor necrosis factor alpha \\
\hline
\end{tabular}

\section{Introduction}

Coronavirus disease 2019 (COVID-19) is a kind of viral pneumonia caused by the novel coronavirus severe acute respiratory syndrome coronavirus 2 (SARS-CoV-2). The emerging COVID-19 pandemic has caused a major global health threat. Also, it has caused a lot of economic damage to most countries of the world (Rothan and Byrareddy 2020). Acute respiratory distress syndrome (ARDS) in severe cases is the main cause of death associated with COVID-19. The deadly uncontrolled systemic inflammatory response results from the release of large amounts of pro-inflammatory cytokines and chemokines. The cytokine storm triggers a violent attack by the immune system on the body, causing ARDS and multiple organ failure, and finally leading to death in severe cases of SARS-CoV-2 infection (Xu et al. 2020; Huang et al. 2020).

The elderly are more likely to get ARDS, so the most severe cases of COVID-19, and the highest rates of death, are among the elderly. However, the elderly are more likely to die from other causes, and the virus is more likely to affect the heart in the elderly, so it has been shown that people with COVID-19 die from heart attacks or stress on the body in general (Yanez et al. 2020; Lloyd-Sherlock et al. 2020). The impaired immune response in older individuals, i.e., immunosenescence and inflammaging play a major role in contributing to the significantly higher mortality rates seen in the elderly (Chen et al. 2021). Immunosenescence and inflammaging are key features of the aging immune system as the accumulation of senescent immune cells contributes to its degradation and, at the same time, an increase in inflammatory phenotypes leads to immune dysfunction (Bajaj et al. 2021). It has been suggested that senotherapeutic agents can reduce RNA virus replication in senescent cells and may have potential therapeutic activity against COVID-19 (Malavolta et al. 2020).

Older adults are less able to respond to new antigens because of the decreased frequency of naive T cells. They cannot frequently clear the virus through an efficient adaptive immune response as in young people. Indeed, antibodysecreting cells and follicular helper $\mathrm{T}$ cells are thought to be less effective than in young patients (Kadambari et al. 2020). As a result of failure to elicit an effective adaptive immune response, the elderly are more likely to have the uncontrolled activation of the innate immune response that leads to cytokine release syndrome and tissue damage (Cunha et al. 2020).

Currently, there is no registered treatment for COVID-19; therefore, scientists are concerned with searching for a drug to treat this disease. The availability of the SARS-CoV-2 vaccines to a large proportion of the population is, unfortunately, something that currently differs greatly between different countries. Furthermore, virus mutations may be a major problem in the effectiveness of the vaccines based on viral-encoded peptides. Many treatment regimens have been tried in the treatment of COVID-19; some show initial promise. On the basis of their antiviral effect against COVID-19 in vitro studies, the anti-rheumatoid chloroquine and hydroxychloroquine with or without azithromycin have received the most attention among antiviral treatments (Gao et al. 2020; Dong et al. 2020). However, the incidence of drug toxicity as QTc prolongation and retinal toxicity should be considered before the use of the drug (Fedson 2016; Singh et al. 2020).

More recently, many investigators have suggested that JAK inhibitors, typically used as anti-inflammatory and antirheumatoid arthritis agents, are a novel treatment strategy for COVID-19. Several clinical trials confirmed that baricitinib has a dual action, demonstrating its ability to block the entry of the virus into target cells and reduce markers of inflammation (Stebbing et al. 2021). It inhibits the proinflammatory cytokine interleukin-6 (IL-6) signaling causing cytokine storm mediated by the JAK-STAT pathway in severe COVID-19 (Zhang et al. 2020; Wu and Yang 2020). Plasma levels of IL-6 have been reported to be a predictive indicator of mortality (Stebbing et al. 2020). Anti-inflammatory combination therapy of baricitinib and dexamethasone in severe COVID-19 was associated with greater improvement in lung function when compared to corticosteroids alone (Seif et al. 2020; Rodriguez-Garcia et al. 2021; Kim et al. 2021; Pum et al. 2021).

Several herbs have been identified as anti-inflammatory and immunomodulating agents that have been suggested to treat coronavirus (Editorial, Nature Plants 2020). It is reported that traditional Chinese medicine has been used in the control of infectious disease and many patients with SARS-CoV infection have benefited from these herbal treatments (Yang et al. 2020; Luo et al. 2020).

Gum resin extract of Boswellia serrata (B. serrata) has been used for centuries to treat a wide range of inflammatory diseases such as arthritis, diabetes, asthma, cancer, or inflammatory bowel (Roy et al. 2019). Zang et al. (2019) confirmed that the anti-inflammatory effect of $B$. serrata could be a potential therapy for the treatment of several inflammatory diseases. Phytochemical examination by thinlayer chromatography showed the main components present in the gum resin of $B$. serrata included terpenoids, phenolic 
compounds, flavonoids, and phenylpropanoids (Ayub et al. 2018). More than 12 different boswellic acids have been identified as components of the $B$. serrata extract, but only KBA (11-keto- $\beta$-boswellic acid) and AKBA (3- $O$-acetyl11 -keto- $\beta$-boswellic acid) have received marked pharmacological interest (Katragunta et al. 2019) (Fig. 1). The limited aqueous solubility and lipophilicity of these pentacyclic triterpenic acids decrease their bioavailability and pharmacological activity. The pharmaceutical development of KBA and AKBA has been extremely limited because of their low oral bioavailability (Sharma and Jana 2020). Other components such as phenolic compounds and flavonoids (quercetin, kaempferol) also play important roles in the anti-inflammatory actions of B. serrata (Gohel et al. 2018).

This review aims to highlight currently published research that has shown evidence, based on the activity of $B$. serrata against pulmonary lesions, oxidative stress, inflammation, immune disturbance, viruses, and secondary microbial infection, for the potential therapeutic effects of boswellic acids (BA) and B. serrata extract against COVID-19 and the conditions associated with it.

\section{Therapeutic basis of the potential use of $B A s$ and $B$. serrata extract against SARS-CoV-2}

Based on scientific evidence, a recent publication suggested that some plant extracts or their components could have a role in the prevention and early treatment of symptoms of viral respiratory infections, and their rational management may also become a complementary treatment for patients with COVID-19 and post-COVID-19 (Firenzuoli et al. 2020). In B. serrata and in Glycyrrhiza glabra, several bioactive ingredients can reduce the production of ILs and leukotrienes. These medicinal plants are widely used in traditional Chinese medicine with some evidence of the effectiveness in the management of hepatitis B, HIV, SARS-CoV, and COVID-19 (Firenzuoli et al. 2020; Gomaa and Abdel-Wadood 2021). In our perspective review, we will discuss and evaluate the different effects of BAs and B. serrata extract that may be useful in combating SARS-CoV-2 and neutralizing any tissue-destructive effects of the virus (Fig. 2).

\section{Methods}

We reviewed the published information up to March 2021. Studies were collected through a search of online electronic databases (academic libraries such as PubMed, Scopus, Web of Science, Google Scholar, and Egyptian Knowledge Bank).

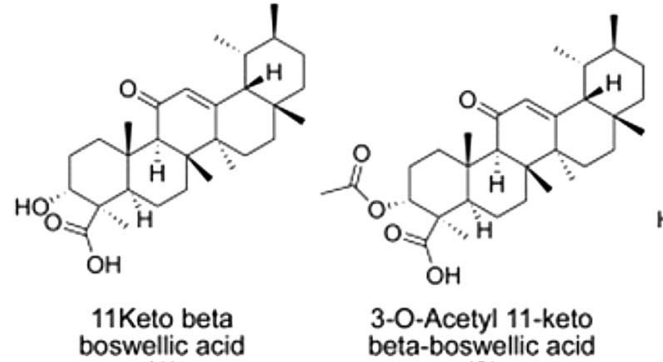

(1)

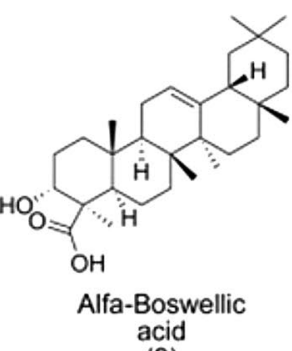

(3)

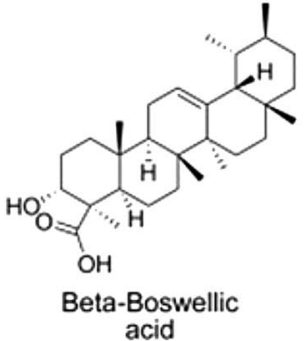

(4)

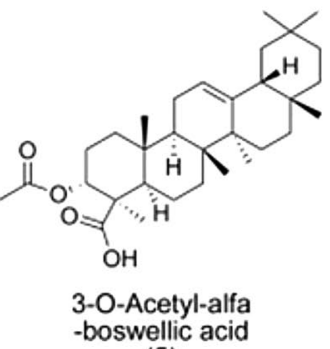

(5)

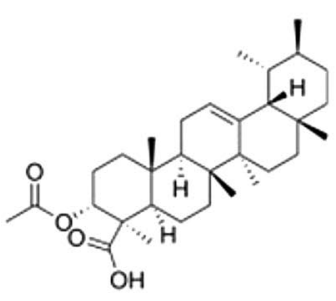

3-O-Acetyl-beta -boswellic acid (6)

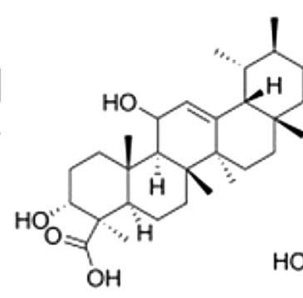

11-hydroxy
-Boswellic acid

(8)

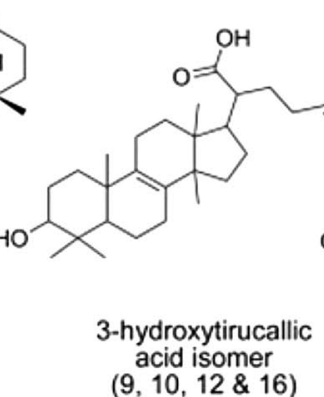

$(9,10,12 \& 16)$

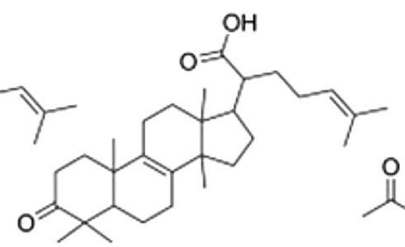

3-oxo-tirucallic (11)

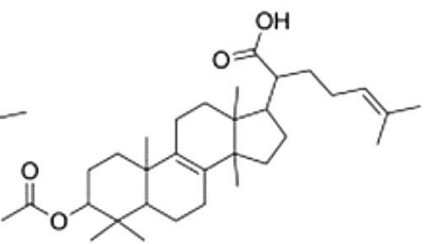

3-O-acetoxy
tirucallic acid isome

(14 \& 15)

Fig. 1 Chemical structure of boswellic acids (Katragunta et al. 2019) 
Fig. 2 Potential therapeutic effects of $B$. serrata gum, B. serrata extract, and boswellic acids in treating similar symptoms experienced by patients with COVID-19

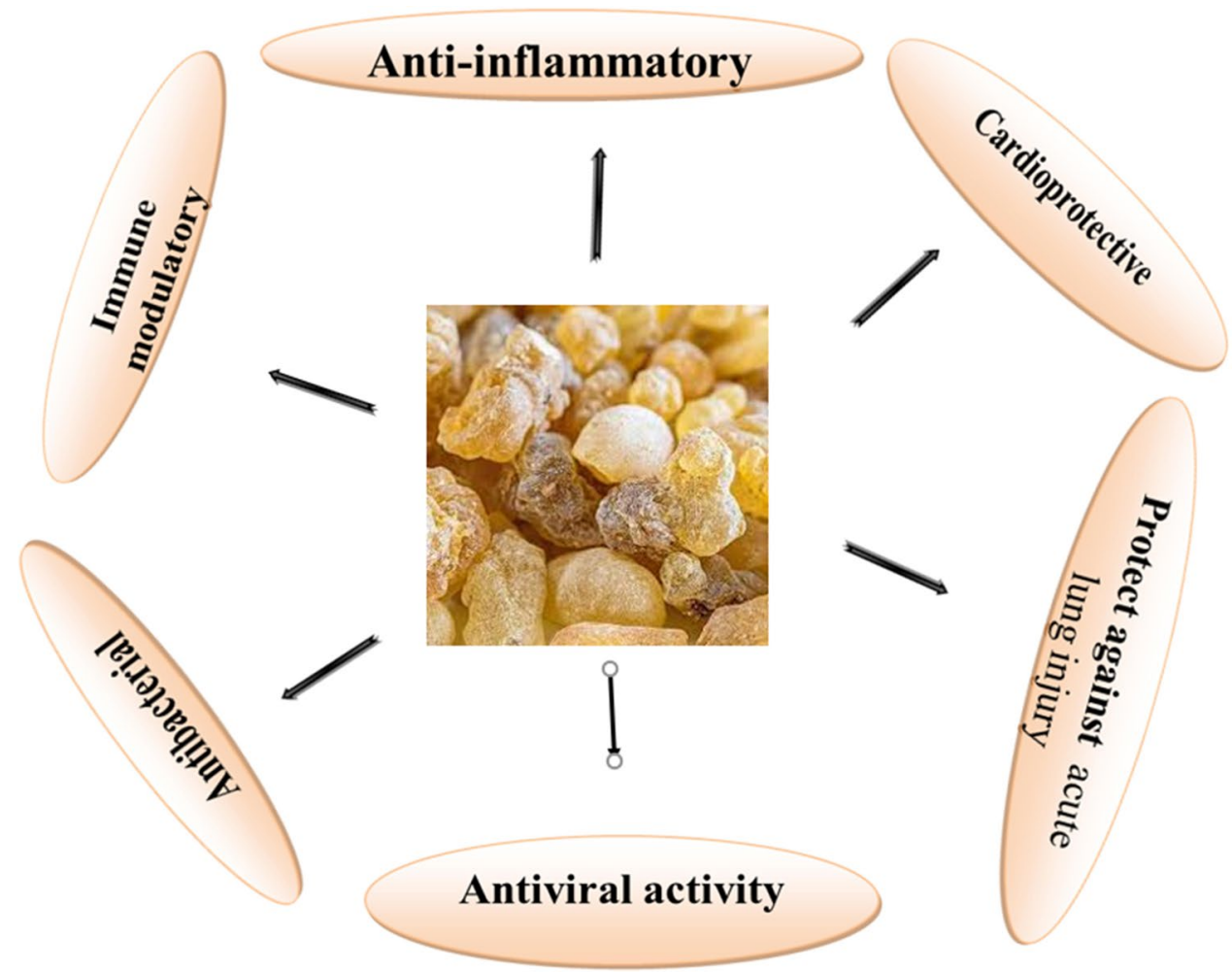

\section{Potential therapeutic effects of boswellic acids/B. serrata extract against SARS-CoV-2-induced pulmonary lesions}

$B$. serrata has been traditionally used in folk medicine for centuries to treat coughs, asthma, and various chronic inflammatory diseases of the lung. It contains many active ingredients responsible for the inhibition of pro-inflammatory cytokines, 5-lipoxygenase, and leukotriene production which is responsible for inflammation (Bosworth et al. 1983; Rashan et al. 2019). Boswellic acids and B. serrata extract have been demonstrated to suppress human leukocyte elastase (HLE), which may be involved in the pathogenesis of cystic fibrosis, chronic bronchitis, ARDS, and emphysema. HLE (a serine protease) is responsible for initiation of injury to the tissues and triggers the process of inflammation. HLE reduces the elasticity of the lungs and removal of mucus. It also constricts the lung passages and damages the secretion of mucus in the lungs. Boswellic acids and $B$. serrata extract have unique character owing to the dual inhibition of 5-lipoxygenase and HLE (Safayhi et al. 1997; Siddiqui 2011; Zhang et al. 2019; Roy et al. 2019). In a recent study, Gilbert et al. (2020) investigated the precise effect of $B$. serrata extract on the production of leukotienes, inflammatory mediators associated with asthma, by studying the structural changes and molecular mechanism of 5-lipoxygenase inhibition by AKBA. They observed that AKBA not only inhibited the formation of classical 5-lipoxygenase products but also caused a switch from the production of pro-inflammatory leukotrienes to the formation of antiinflammatory LOX-isoform-selective modulators.

Moreover, B. serrata extract could combat bleomycininduced injury, collagen accumulation, airway dysfunction, and pulmonary fibrosis in rats (Ali and Mansour 2011). Additionally, B. serrata extract showed a direct concentration-dependent relaxant effect on rat trachea precontracted with either $\mathrm{ACh}$ or $\mathrm{KCl}$ in vitro. These results may partly contribute to validating the traditional use of $B$. serrata in treating lung diseases (Hewedy 2020).

The anti-asthmatic activity of $B$. serrata was confirmed early, in a double-blind placebo controlled clinical study with $300 \mathrm{mg}$ thrice daily dose for 6 weeks (Gupta et al. 1998). In other clinical studies by Houssen et al. (2010) and Al-Jawad et al. (2012) B. serrata extract was effective in the management of bronchial asthma owing to its natural antiinflammatory and leukotriene inhibitory actions. It reduces the need for inhalation therapy with corticosteroids and long-acting beta-agonists (Ferrara et al. 2015). Moreover, Liu et al. (2015) and Zhou et al. (2015) demonstrated that boswellic acid attenuates asthma phenotypes by downregulation of GATA3 via pSTAT6 inhibition. These results suggest that $B$. serrata might be effective in controlling the inflammation process in asthmatic conditions by inhibiting the production of pro-inflammatory mediators (Rashan et al. 2019). A more recent study suggested that $B$. serrata ethanolic 
extracts possess significant anti-inflammatory activities in HL-60 cell lines and in BALB/c mice. This study is further support for use of B. serrata in the treatment of allergy, asthma, and other lung disorders (Soni et al. 2020). These therapeutic effects of $B$. serrata against induction of pulmonary lesions may be beneficial for the prevention of pulmonary lesions caused by COVID-19.

\section{Potential therapeutic effects of boswellic acids/B. serrata extract against SARS-CoV-2-induced modification of cellular redox, inflammation, tissue injury, and severe hypercoagulability}

There are a large number of findings in the literature showing the antioxidant and anti-inflammatory effects of $B$. serrata and its phytochemicals. They have multiple modes of action, e.g., by inhibiting interleukin-1 $\beta$ (IL-1 $\beta$ ), IL-6, inducible nitric oxide synthase (iNOS) mRNA expression, NF-B phosphorylation, synthesis of leukotriene and 5-lipoxygenase activity, and ameliorating oxidative stress (Miao et al. 2019; Efferth and Oesch 2020). Several investigations have suggested that boswellic acids and $B$. serrata extract can counteract free radicals that cause inflammation and thereby prevent tissue damage. It has been shown that $B$. serrata treatment alleviated oxidative stress and improved total antioxidant capacity in the liver, and reduced the expression of TNF $\alpha$, NF- $\kappa B$, TGF $\beta$, IL-6, and cyclooxygenase-2 (COX-2) (Eltahir et al. 2020). On a histopathological level, B. serrata treatment also exhibited antifibrotic activity (Eltahir et al. 2020). The anti-inflammatory activity of $B$. serrata extracts on endothelial cells leads to a therapeutic application for cardiovascular and respiratory health (Bertocchi et al. 2018).

Several investigations indicate that the antioxidant, antiinflammatory, and immunomodulatory effects are not limited to one specific type of Boswellia (Efferth and Oesch 2020). Boswellia species showed 5-lipoxygenase and cyclooxygenase $(\mathrm{COX}-1,2)$ inhibitory activity (Siddiqui 2011). In addition, boswellic acids and other derivatives have been demonstrated to reduce the production of inflammatory cytokines, including IL-1, IL-2, IL-6, IFN $\gamma$, and $\mathrm{TNF} \alpha$ that are ultimately directed to tissue destruction such as lung, cartilage, and insulin-producing cells. The mechanism of the anti-inflammatory therapeutic effects may be through direct interaction with IкB kinases and inhibiting nuclear factor- $\mathrm{kB}$-regulated gene expression (Ammon 2016). The main mechanism of $B$. serrata may also be through the elimination of the senescent cells that secrete a group of proinflammatory cytokines, chemokines, and proteases called the senescence-associated secretory phenotype (SASP) (Xu et al. 2018). These pro-inflammatory mediators are responsible for tissue dysfunction during aging, obesity, and inflammatory diseases (Muñoz-Espín and Serrano 2014). Natural agents such as quercetin and kaempferol (components of B. serrata) have been reported to eliminate cellular senescence in vitro and in mice (Gohel et al. 2018; Lewinska et al. 2020). In vitro and in vivo evidence showed that AKBA significantly promotes peripheral nerve repair and Schwann cell proliferation after rat sciatic nerve injury (Jiang et al. 2018).

The anti-inflammatory and antioxidative effects displayed by $B$. serrata extract suggest a new supportive treatment option in acute systemic inflammation and wound healing (Loeser et al. 2018; Pengzong et al. 2019). Also, B. serrata extract and boswellic acids both counteract free radicals (ROS) and significantly protect the intestinal epithelial barrier from inflammatory damage and inhibit NF-B phosphorylation induced by inflammatory stimuli (Catanzaro et al. 2015). Additionally, acetyl-11-keto-beta-boswellic, in a dose-dependent manner, prevents testicular torsion/detorsion injury in rats with induced upregulation of 5-LOX/LTB4 and $\mathrm{p} 38$-MAPK/JNK/Bax pathways and their concomitant inflammatory and apoptotic pathways. It works by inhibiting the 5-LOX/LTB4 and p38-MAPK/JNK/Bax/Caspase-3 pathways (Ahmed et al. 2020). This protective effect is mediated by suppressing levels of intracellular oxygen free radicals, lipid peroxidation, oxidative DNA damage, and inflammation (Sadeghnia et al. 2017; Ahmad et al. 2019). The neuroprotective activities of Boswellia extract and boswellic acids mediated through the inhibition of the oxidative stress were observed also against glutamate toxicity-induced cell injury (Bai et al. 2019; Rajabian et al. 2016, 2020).

There are some clinical studies published in peerreviewed scientific journals that draw conclusions about the clinical benefit of $B$. serrata and its phytochemicals in chronic inflammatory diseases. The clinically measurable improvements with $B$. serrata and its phytochemicals can be achieved in osteoarthritis, multiple sclerosis, bronchial asthma, and psoriasis (Efferth and Oesch 2020; Yu et al. 2020). Moreover, in a preliminary controlled trial in ischemic stroke, $B$. serrata could improve clinical outcomes in the early phases of stroke along with promising changes in plasma inflammatory factors. The levels of plasma inflammatory markers (TNF $\alpha$, IL-1 $\beta$, IL-6, IL-8, and $\mathrm{PGE}_{2}$ ) were significantly decreased in the group of patients who received B. serrata for 7 days (Baram et al. 2019). Moreover, boswellic acid and AKBA show promising anti-platelet aggregation effect, anti-profibrotic mechanisms, and improve vascular remodeling by reducing the enhanced oxidative stress and inflammation through the TGF $\beta 1 / \mathrm{Smad} 3$ pathway (Tawfik 2016; Shang et al. 2016). These data demonstrate that $B$. serrata extract and boswellic acids may have beneficial effects against COVID-19-induced oxidative stress, inflammation, clotting formation, and microthrombus, the main cause of the risk of damage to major organs. 


\section{Potential therapeutic effects of boswellic acids and $B$. serrata extract against SARS-CoV-2-induced immune dysregulation}

Autoimmune diseases are characterized by an uncontrolled overwhelming immune system reaction with enhanced $\mathrm{T}$ cell proliferation. B. serrata extracts and their active ingredients including boswellic acids affect the immune system in different ways (Table 1). Boswellic acids have two different actions on cellular defense: they promoted lymphocyte proliferation in small doses while higher concentrations are inhibitory. In terms of the humoral defense system, boswellic acids also reduced primary antibody titers at higher doses; however, lower doses increased secondary antibody titers. Moreover, boswellic acids enhance the phagocytosis of macrophages (Mikhaeil et al. 2003; Pungle et al. 2003; Ammon 2011; Siddiqui 2011). Beghelli et al. (2017) suggested that B. serrata has a promising potential to modulate not only inflammation/oxidative stress but also immune dysregulation.

It is noteworthy that $B$. serrata gum resin extract decreased IA(2)-antibody in a patient with late-onset autoimmune diabetes of the adult (Schrott et al. 2014). Recently, Franic et al. (2020) confirmed that B. serrata gum resin extract inhibits the production of autoantibodies, GAD65 and IA2, markers of autoimmunity, and prevents autoimmune diabetes. Moreover, Aldahlawi et al. (2020) suggested that B. serrata essential oil (BSEO) has immunomodulatory effects on $\mathrm{T}$ cells and dendritic cells. It deflects the differentiation of monocytes into immature dendritic cells (DCs). Stimulation of immature DCs using BSEO was not able to generate full DC maturity. These results can be used to generate DCs with properties capable of inducing tolerance in hypersensitivity and autoimmune diseases (Aldahlawi et al. 2020).

It is important to emphasize the ability of $B$. serrata to mitigate the uncontrolled activation of the innate immune response and suppress the release of cytokines. It has been observed that lipophilic extract of $B$. carterii gum resin inhibited the proliferation, degranulation capacity, and secretion of inflammatory mediators of physiologically relevant anti-CD3 and anti-CD28 activated human T lymphocytes in a non-toxic concentration (ZimmermannKlemd et al. 2020). B. serrata or boswellic acids inhibit the production of pro-inflammatory cytokines including TNF $\alpha$, IL-1, IL-2, IL-6, IL-12, and IFN $\gamma$ (Gayathri et al. 2007; Gomaa et al. 2019). Also, many investigators confirmed that $B$. serrata extracts and their active ingredients boswellic acids significantly inhibited the release of proinflammatory cytokines, such as TNF $\alpha$, IL-1 $\beta$, IL-6, IL-8, and IL-10 (Schmiech et al. 2019, 2021).
The immunomodulatory effects of B. serrata extract/ boswellic acids have a wide range of clinical applications. AKBA enhances osteoblast differentiation in rheumatoid arthritis (RA)-related bone loss disease by inhibiting TNF $\alpha$ and NF- $\mathrm{KB}$ where TNF $\alpha$ suppresses osteoblast differentiation by activating NF- $\mathrm{kB}$ (Bai et al. 2018). A standardized $B$. serrata extract reduces disease activity in patients with relapsing-remitting multiple sclerosis by a significant increase in regulatory $\mathrm{CD} 4^{+} \mathrm{T}$ cell markers, and a significant reduction in IL-17A-producing $\mathrm{CD} 8^{+} \mathrm{T}$ cells and bioactive 5-LOX-derived lipid mediators (Stürner et al. 2018; Stürner et al. 2020). It is evident from previous results that $B$. serrata exracct and boswellic acids may have the potential to enhance the adaptive immune response, and suppress the uncontrolled activation of the innate immune response that leads to cytokine release syndrome and tissue damage in elderly people with COVID-19.

\section{Broad antiviral effect of boswellic acids and $B$. serrata extract}

Although there is no currently published study showing $B$. serrata activity against SARS-CoV-2, several investigators have shown that $B$. serrata possesses broad antiviral activity. The antiviral effect of $B$. serrat $a$ was investigated by Goswami et al. (2018). They reported that B. serrata and BA potently inhibited wild-type and a clinical isolate of HSV-1. The inhibitory effect was significant at $1 \mathrm{~h}$ post-infection and effective up to $4 \mathrm{~h}$. The mechanism of the antiviral effect of $B$. serrata extract and BAs was through blocking of NF-кB, necessary for virus replication. B. serrata gum resin extract also has antiviral activity against Chikungunya virus (CHIKV). It blocks the entry of Chikungunya virus Env-pseudotyped lentiviral vectors and inhibited CHIKV infection in vitro. Moreover, $B$. serrata gum resin extract exhibits antiviral activity against vesicular stomatitis virus, vector particles, and viral infections to the same extent, indicating a broad antiviral activity (Von Rhein et al. 2016).

The strong antiviral activity of the total extract of $B$. serrata gum resin against the herpes virus was confirmed by Badria et al. (2003a, b). They reported that the activity of the total extract is much greater than that of the individual components. Furthermore, pentacyclic triterpenoids have been documented to have a potential therapeutic role in the treatment of virus infections. For example, research groups have investigated the activity against $\mathrm{HIV}, \mathrm{HCV}$, influenza, and other viruses of natural pentacyclic triterpenoids and their semisynthetic derivatives (Xiao et al. 2018). The mechanism of antiviral activity of triterpenoids may be through inhibiting the entry of viruses such as Ebola, Marburg, HIV, and influenza A virus. This action is achieved by wrapping the HR2 domain prevalent in viral envelopes (Si et al. 2018). In 


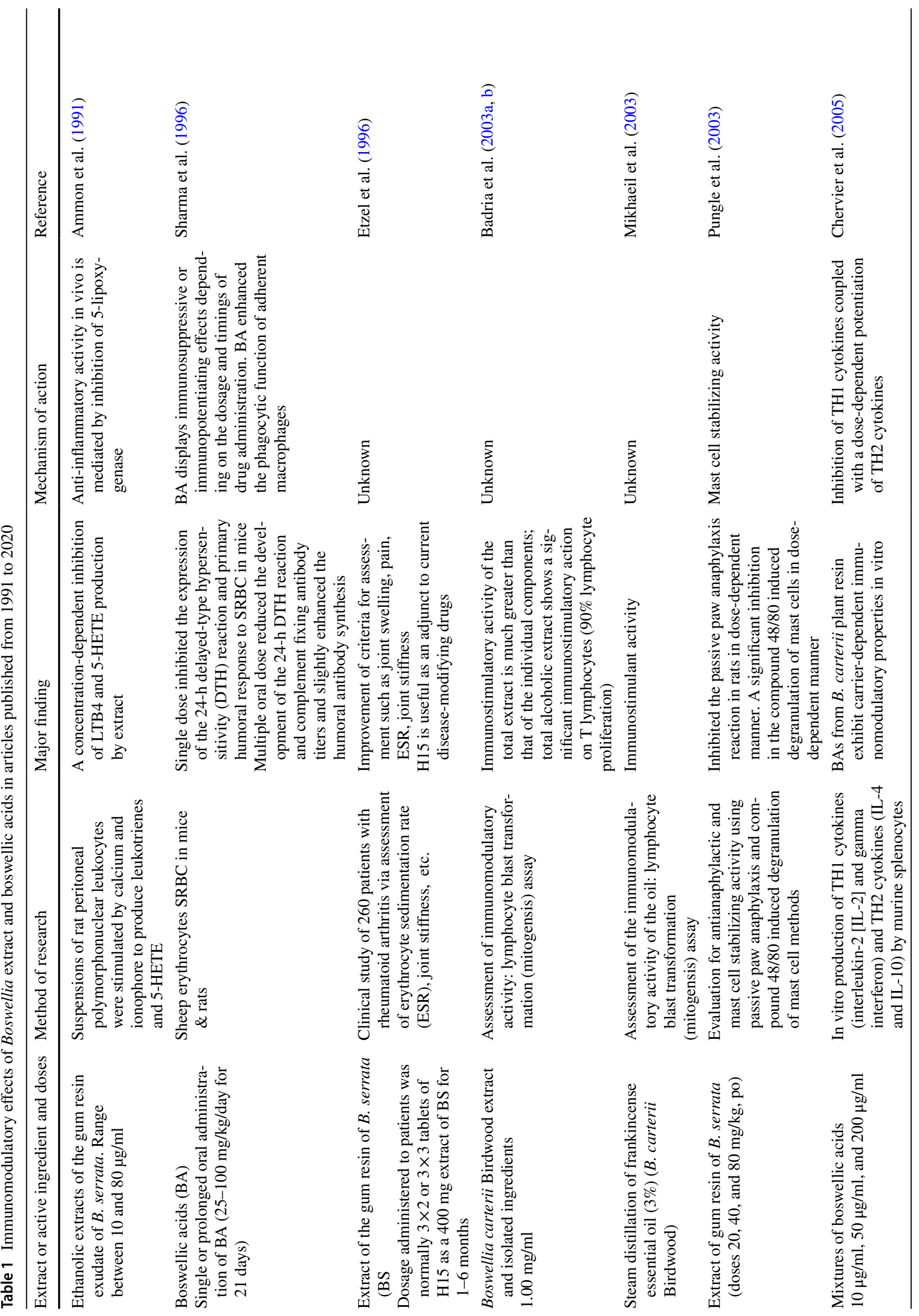




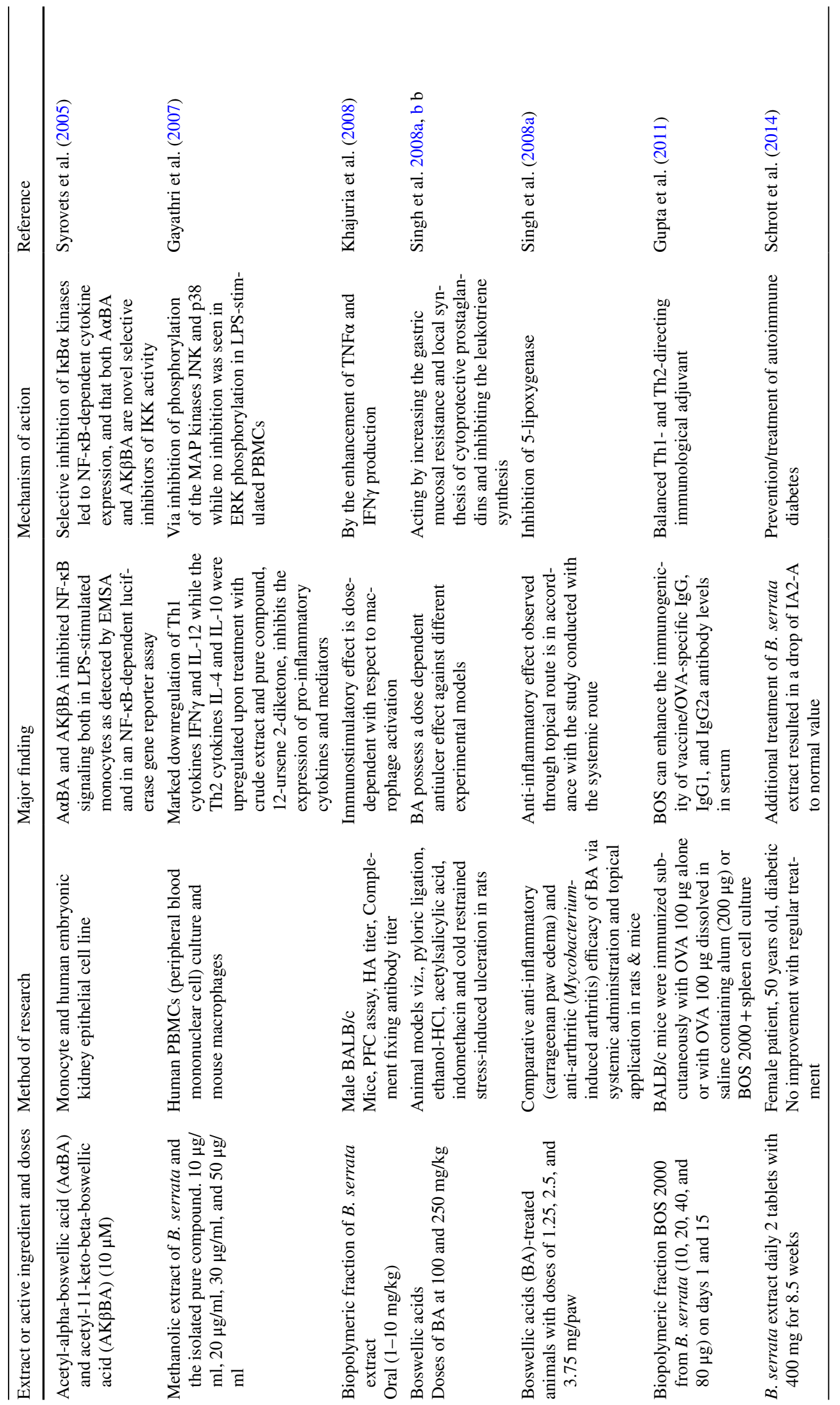




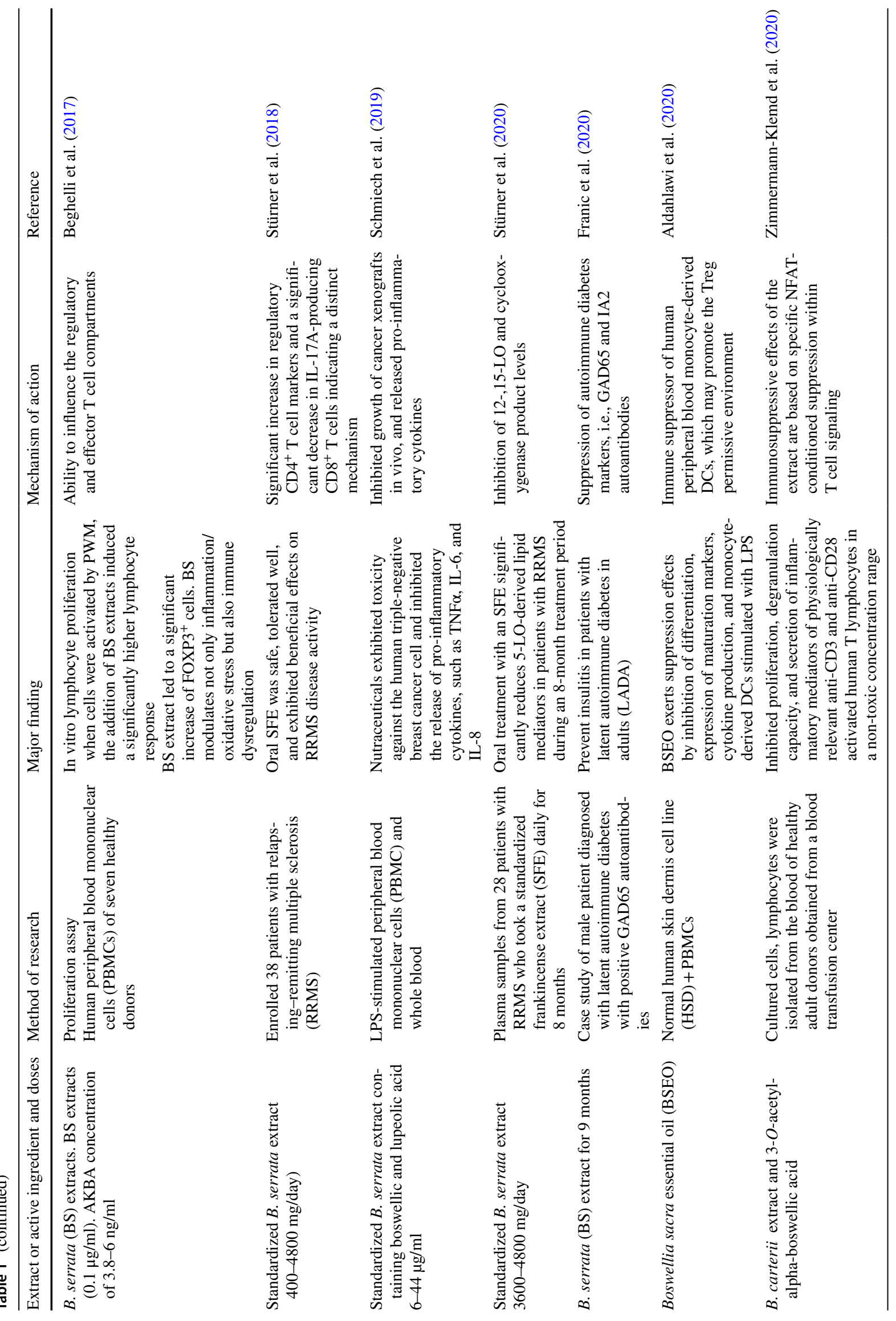


addition to the antiviral activity of boswellic acids, flavonoids of $B$. serrata possess inhibitory activity against many viruses (Zakaryan et al. 2017). On the basis of these studies, it is clear that $B$. serrata extract and boswellic acids have a broad antiviral activity that may be beneficial in the fight against SARS-CoV-2.

\section{Potential therapeutic effects of boswellic acids and B. serrata extract against COVID-19-induced secondary microbial infections}

COVID-19 infection results in significant and persistent lymphopenia in $85 \%$ of patients. Furthermore, a person taking immunosuppressants, such as corticosteroids and monoclonal antibodies, may experience severe lymphocytopenia. Because lymphocytes play an important role in the immune defense function against infection, patients with COVID19 are highly susceptible to bacterial and fungal secondary infections causing a high mortality rate in patients with COVID-19 (Bhatt et al. 2021). About 3.6-13\% of patients with COVID-19 developed a secondary bacterial or fungal infection and the mortality rate among these patients was about 33.3-56.7\% (Khurana et al. 2021; Vijay et al. 2021). Also, it has been verified that major anaerobic pathogens Tannerella forsythia and Porphyromonas gingivalis in periodontitis are associated with a higher risk of developing a severe secondary infection in patients with COVID-19 (Aquino-Martinez et al. 2021; Marouf et al. 2021; Şehirli et al. 2021), and importantly that patients with COVID-19 have a high probability of suffering from an invasive fungal infection such as mucormycosis, cryptococcosis, aspergillosis, or candidiasis as secondary infection (Song et al. 2020).

Several studies have noted that $B$. serrata extract or boswellic acids are bacteriostatic at low concentration or bactericidal at high concentration for many gram-positive and gram-negative bacteria in vitro and in vivo. According to the findings of Bakhtiari et al. (2019), hydro-alcoholic extract of $B$. serrata is more effective against Candida albicans, Candida glabrata, Candida krusei, and Streptococcus mutans than organic extract. Hydro-alcoholic extract of $B$. serrata was most effective against $C$. albicans and S. mutans. B. serrata also showed antifungal effects (Camarda et al. 2007). Kasali et al.(2002) and Schillaci et al. (2008) Also observed that $B$. serrata essential oil inhibited C. albicans, Staphylococcus aureus, and Staphylococcus epidermidis biofilm formation. AKBA showed an inhibitory effect on all the oral cavity microorganisms. It showed concentration-dependent killing of $S$. aureus and $S$. mutans. Moreover, AKBA blocked the formation of biofilms generated by $S$. aureus $S$. epidermidis, S. mutants, and Actinomyces viscosus (Raja et al. 2011a, b).
The periodontal infection is polymicrobial of different bacterial species but aggressive forms of this disease have been associated with specific Gram-negative bacteria Aggregatibacter actinomycetemcomitans. B. serrata is effective against $A$. actinomycetemcomitans which may be useful as a suitable oral health medicine and treatment of periodontal infection (Maraghehpour et al. 2016). A double-blind randomized controlled trial was conducted among high school students with moderate plaque-induced gingivitis. $B$. serrata extract has been safely used to treat and improve the gum health of students. It demonstrated satisfactory medicinal properties, which may be superior to scaling and root planing (SRP) as a conventional method for removing dental plaque (Khosravi Samani et al. 2011).

Many investigators have suggested that AKBA could be a useful agent for developing an antibacterial agent against oral pathogens and it has the potential for use in mouthwash to prevent and treat oral infection (Raja 2011a, b; Patel and Patel 2014). However, Sabra and Al-Masoudi (2014) suggested that $B$. serrata chewing gum is a safe and low-cost herbal product, which supports mouth hygiene for all ages. It improves buccal/oral cavity hygiene by antimicrobial effects which decrease the sources of microbial infection in the buccal/oral cavity as tested by counting microbial contents of the buccal/oral cavity through microbial identification of saliva.

Several researchers demonstrated the antifungal activity of $B$. serrata. Essential oil of B. serrata has shown broad antifungal activity against many types of fungal infections and is likely to be a good source of antifungal agents to prevent fungal infections and mycotoxin contamination (Venkatesh et al. 2017). Furthermore, the antimicrobial activity of $B$. serrata essential oil has been demonstrated against fungal infections, and it has shown synergistic antifungal activity in combination with azoles against the azole-resistant $C$. albicans (Sadhasivam et al. 2016). Acetone extract of $B$. serrata was shown to be more effective than ethanol against drug-resistant Aspergillus fumigatus isolated from Diyala patients and has excellent potential as an antifungal agent (Abdul Sattar et al. 2019).

Given the poor bioavailability of $B$. serrata after oral administration (Sharma et al. 2004; Siddiqui 2011; Sharma et al. 2020), chewing B. serrata gum may lead to better absorption of active ingredients from buccal mucosa. Moreover, the art of chewing $B$. serrata has other benefits: $B$. serrata has antibacterial, antifungal, and antiviral activities against oral pathogens and it has great potential for use in preventing and treating oral infections (Raja et al. 2011a, b; Hasson et al. 2011; Bakhtiari et al. 2019; Rad and Taherian 2020). However, chewing $B$. serrata gum may not be the most effective or easiest way to give $B$. serrata. In addition, the bioavailability of the active ingredients after conventional use of chewable B. serrata has not yet been published. To overcome the poor 
bioavailability of the concentrated or isolated boswellic acids, attempts have been made to enhance the bioavailability by the combination of Piper longum (long pepper) and by producing specific compounds such as boswellic acids attached to phospholipids or incorporated into micelles (Hüsch et al. 2013; Meins et al. 2018; Vijayarani et al. 2020). On the basis of the aforementioned studies, it is clear that $B$. serrata extract and boswellic acids may have a therapeutic effect against virusinduced secondary microbial infection and may be effective in preventing COVID-19 causing secondary infection and COVID-19 causing complications.

\section{Toxicity and safety of $B$. serrata extract and boswellic acids}

Recent studies confirmed that $B$. serrata extract and boswellic acids possess a high safety margin. Acute oral toxicity studies did not exhibit mortality or signs of toxicity in Wistar rats up to $2000 \mathrm{mg} / \mathrm{kg}$ (Alluri et al. 2019). In mice, no death was recorded following the single-dose administration of $B$. serrata extract at a dose of up to $5 \mathrm{~g} / \mathrm{kg}$ (Gomaa et al. 2019). Oral administration of the extract for 28 consecutive days did not exhibit any sign of behavioral toxicity and did not show significant changes of biomarkers of hepatic and renal functions as well as the histological characters in rats (Al-Yahya et al. 2020). Moreover, Alluri et al. (2019) demonstrated that repeated oral dose of $B$. serrata extract for 28 days in Wistar rats did not show dose-related signs of toxicity on the hematology, clinical chemistry, mutagenic, and clastogenic parameters. In previous studies, it was observed that acute oral LD50 of $B$. serrata extract was greater than $5000 \mathrm{mg} / \mathrm{kg}$ in female and male Sprague Dawley rats, and repeated oral dose for 28 or 90 days in Sprague Dawley rats showed no significant adverse changes in hematology, clinical chemistry, gross necropsy, histopathology examinations, and hepatic DNA fragmentation at 30,60, or 90 days of treatment (Krishnaraju et al. 2010; Singh et al. 2012). Boswellic acids have the same wide spectrum of safety as $B$. serrata extract. They did not exhibit any sign of toxicity up to $2 \mathrm{~g} / \mathrm{kg}$ administered orally or intraperitoneally and daily oral administration of BAs in three doses (low and very high) to rats and monkeys revealed no significant changes in general behavior or clinical, hematological, biochemical, and pathological parameters (Singh et al. 1996; Lalithakumari et al. 2006).

\section{Perspectives}

We propose that $B$. serrata extract in small to moderate dose (100-200 mg/day) can be used in early stages in mild to moderate symptoms of COVID-19 to enhance the adaptive immune response. However a large dose of $B$. serrata extract or boswellic acid can be used to suppress the uncontrolled activation of the innate immune response that leads to cytokine storm. Because of the low oral bioavailability and improvement of buccal/oral cavity hygiene, traditional use by chewing $B$. serrata gum may be more beneficial in mild to moderate symptoms and as prophylactic. Also, it may be the cheapest option for a lot of poorer people; however, it may not be the most effective or easiest way of administering $B$. serrata. $B$. serrata extract or boswellic acid may be used also as a prophylactic agent in combination with other natural antiviral agents such as licorice for the prevention of progression of the COVID-19 (Gomaa and Abdelwadood 2021). This combination can be considered as one of the best suggested natural regimens for the prevention of COVID-19. Since this regimen has a high safety margin, it is now under clinical trial to determine its therapeutic efficacy in patients with COVID-19 (ClinicalTrials.gov Identifier NCT04487964).

\section{Conclusions}

Given the pharmacological and clinical evidence, there may be a use for $B$. serrata in treating similar symptoms experienced by patients with COVID-19. The potential therapeutic effects of boswellic acids and B. serrata extract are attributed mainly to its anti-inflammatory, immunomodulatory, cardioprotective, anti-platelet aggregation, antibacterial, antifungal, and broad antiviral activity. Because of the low oral bioavailability and improvement of buccal/oral cavity hygiene, traditional use by chewing $B$. serrata gum may be a good, and only, option for poorer people. The main mechanism of therapeutic effects may be through direct interaction

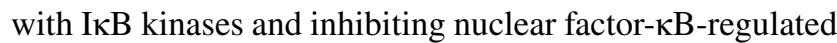
gene expression. However, the most recent mechanism proposed that BA not only inhibited the formation of classical 5-lipoxygenase products but also caused a switch from the production of pro-inflammatory leukotienes to formation of anti-inflammatory LOX-isoform-selective modulators. Although the non-clinical studies acknowledge the usefulness of boswellic acids and $B$. serrata extract in treating COVID-19, these data reinforce the idea that more clinical results are required to determine with certainty whether there is sufficient evidence of the benefits of $B$. serrata extract and boswellic acids against COVID-19.

Author contributions AAG: resources, writing-original draft, writing - review and editing, supervision. HSM: writing - review and editing. RBA: writing - review and editing. MAG: writing-review and editing.

Funding This study was not funded by any specific grant from funding agencies in the public, commercial, or not-for-proft sectors. 
Data availability Data on relevant human studies in the current review (https://drive.google.com/file/d/17YZvAhCFoBMV6vdnjLFzfNN5 2 vtpCKri/view?usp=sharing)

\section{Declarations}

Conflict of interest The author declares no conflict of interest.

Ethical approval This article does not contain any studies with human participants or animals performed by any of the authors.

Informed consent Not applicable.

\section{References}

Abdul SO, Fadhel S, Ismael T, Hussain A (2019) Antifungal activity of Boswellia serrata gum extracts on antifungal drugs resistant Aspergillus fumigatus isolated from Diyala patients. Indian $\mathbf{J}$ Public Health Res Dev 10(11):4929-4934. https://doi.org/10. 37506/ijphrd.v10i11.8914

Ahmed S, Khan SA, Kindelin A, Mohseni T, Bhatia K, Hoda M, Ducruet AF (2019) Acetyl-11-keto- $\beta$-boswellic acid (AKBA) attenuates oxidative stress, inflammation, complement activation and cell death in brain endothelial cells following OGD/ reperfusion. Neuromol Med 21:505-516. https://doi.org/10.1007/ s12017-019-08569-Z

Ahmed MAE, Ahmed AAE, El Morsy EM (2020) Acetyl-11-keto$\beta$-boswellic acid prevents testicular torsion/detorsion injury in rats by modulating 5-LOX/LTB4 and p38-MAPK/JNK/Bax/caspase-3 pathways. Life Sci 260:118472. https://doi.org/10.1016/j. lfs. 2020.118472

Aldahlawi AM, Alzahrani AT, Elshal MF (2020) Evaluation of immunomodulatory effects of Boswellia sacra essential oil on T cells and dendritic cells. BMC Complement Med Ther 20(1):352. https://doi.org/10.1186/s12906-020-03146-5

Ali EN, Mansour SZ (2011) Boswellic acids extract attenuates pulmonary fibrosis induced by bleomycin and oxidative stress from gamma irradiation in rats. Chin Med 6:36. https://doi.org/10. 1186/1749-8546-6-36

Al-Jawad FH, Al-Razzuqi RA, Hashim HM et al (2012) Glycyrrhiza glabra versus Boswellia carterii in chronic bronchial asthma: a comparative study of efficacy. Indian J Allergy Asthma Immunol 26:6-8

Alluri VK, Dodda S, Kilari EK et al (2019) Toxicological assessment of a standardized Boswellia serrata gum resin extract. Int J Toxicol 38:423-435. https://doi.org/10.1177/1091581819858069

Al-Yahya AA, Asad M, Sadaby A et al (2020) Repeat oral dose safety study of standardized methanolic extract of Boswellia sacra oleo gum resin in rats. Saudi J Biol Sci 27:117-123. https://doi.org/ 10.1016/j.sjbs.2019.05.01

Ammon HP (2011) Modulation of the immune system by Boswellia serrata extracts and boswellic acids. Phytomedicine 15:334. https://doi.org/10.1016/j.phymed.2010.03.003

Ammon HP (2016) Boswellic acids and their role in chronic inflammatory diseases. Adv Exp Med Biol 928:291-327

Ammon HP, Mack T, Singh GB, Safayhi H (1991) Inhibition of leukotriene $\mathrm{B} 4$ formation in rat peritoneal neutrophils by an ethanolic extract of the gum resin exudates of Boswellia serrata. Planta Med 57:203-207

Aquino-Martinez R, Hernández-Vigueras S (2021) Severe COVID19 lung infection in older people and periodontitis. J Clin Med 10:279. https://doi.org/10.3390/jcm10020279
Ayub M, Hanif M, Sarfraz R et al (2018) Biological activity of Boswellia serrata Roxb. oleo gum resin essential oil: effects of extraction by supercritical carbon dioxide and traditional methods. Int J Food Prop 21:808-820

Badria FA, Abu-Karam M, Mikhaeil BR et al (2003a) Anti-herpes activity of isolated compounds from frankincense. Biosci Biotechnol Res Asia 1(1):1-10

Badria FA, Mikhaeil BR, Maatooq GT, Amer MM (2003b) Immunomodulatory triterpenoids from the oleogum resin of boswellia carterii birdwood. Z Naturforsch C J Biosci 58:505516. https://doi.org/10.1515/znc-2003-7-811

Bai F, Chen X, Yang H, Xu HG (2018) Acetyl-11-keto- $\beta$-boswellic acid promotes osteoblast differentiation by inhibiting tumor necrosis factor- $\alpha$ and nuclear factor- $\kappa b$ activity. J Craniofac Surg 29:1996-2002. https://doi.org/10.1097/SCS.0000000000 004691

Bai J, Gao Y, Chen L, Yin Q, Lou F, Wang Z, Xu Z et al (2019) Identification of a natural inhibitor of methionine adenosyltransferase $2 \mathrm{~A}$ regulating one-carbon metabolism in keratinocytes. EBioMedicine 39:575-590. https://doi.org/10.1016/j.ebiom.2018. 12.036

Bajaj V, Gadi N, Spihlman AP, Wu SC, Choi CH, Moulton VR (2021) Aging, immunity, and COVID-19: how age influences the host immune response to coronavirus infections? Front Physiol 11:571416. https://doi.org/10.3389/fphys.2020.571416

Bakhtiari S, Nematzade F, Hakemi-Vala M, Talebi G (2019) Phenotypic investigation of the antimicrobial effect of organic and hydro-alcoholic extracts of boswellia serrata on oral microbiota. Front Dent 16:386-392. https://doi.org/10.18502/fid.v16i5.2287

Baram SM, Karima S, Shateri S et al (2019) Functional improvement and immune-inflammatory cytokines profile of ischaemic stroke patients after treatment with boswellic acids: a randomized, double-blind, placebo-controlled, pilot trial. Inflammopharmacology 27:1101-1112. https://doi.org/10.1007/s10787-019-00627-z

Beghelli D, Isani G, Roncada P et al (2017) Antioxidant and ex vivo immune system regulatory properties of Boswellia serrata extracts. Oxid Med Cell Longev. https://doi.org/10.1155/2017/ 7468064

Bertocchi M, Isani G, Medici F, Andreani G, Tubon Usca I, Roncada P, Forni M, Bernardini C (2018) Anti-inflammatory activity of Boswellia serrata extracts: an in vitro study on porcine aortic endothelial cells. Oxid Med Cell Longev. https://doi.org/10.1155/ 2018/2504305

Bhatt K, Agolli A, Patel MH et al (2021) High mortality co-infections of COVID-19 patients: mucormycosis and other fungal infections. Discoveries (Craiova) 9(1):e126. https://doi.org/10. $15190 /$ d. 2021.5

Bosworth CE, vanDonzel E, Lewis E, Pellet CH (1983) The encyclopedia of Islam. EJ Bril, Leiden

Camarda L, Dayton T, Di Stefano V, Pitonzo R, Schillaci D (2007) Chemical composition and antimicrobial activity of some oleogum resin essential oils from Boswellia spp. (Burseraceae). Ann Chim 97:837-844

Catanzaro D, Rancan S, Orso G, Dallcqua S, Brun P, Giron MC, Carrara $\mathrm{M}$ et al (2015) Boswellia serrata preserves intestinal epithelial barrier from oxidative and inflammatory damage. PLoS One 10(5):e0125375. https://doi.org/10.1371/journal.pone.0125375

Chen Y, Klein SL, Garibaldi BT et al (2021) Aging in COVID-19: vulnerability, immunity and intervention. Ageing Res Rev 65:101205. https://doi.org/10.1016/j.arr.2020.101205

Chervier MR, Ryan AE, Lee DY, Zhongze M, Wu-Yan Z, Via CS (2005) Boswellia carterii extract inhibits TH1 cytokines and promotes $\mathrm{TH} 2$ cytokines in vitro. Clin Diagn Lab Immunol 1:575-580

Cunha LL, Perazzio SF, Azzi J, Cravedi P, Riella LV (2020) Remodeling of the immune response with aging: immunosenescence 
and its potential impact on COVID-19 immune response. Front Immunol 11:1748. https://doi.org/10.3389/fimmu.2020.01748

Cunningham AC, Goh HP, Koh D (2020) Treatment of COVID-19: old tricks for new challenges. Crit Care 24(1):91. https://doi. org/10.1186/s13054-020-2818-6

Dong L, Hu S, Gao J (2020) Discovering drugs to treat coronavirus disease 2019 (COVID-19). Drug Discov Ther 14:58-60. https://doi.org/10.5582/ddt.2020.01012

Editorial (2020) Redeploying plant defences. Nat Plants 6:177

Lloyd-Sherlock P, Ebrahim S, Geffen L, McKee M (2020) Bearing the brunt of covid-19: older people in low and middle income countries. BMJ. https://doi.org/10.1136/bmj.m1052

Efferth T, Oesch F (2020) Anti-inflammatory and anti-cancer activities of frankincense: targets, treatments and toxicities. Semin Cancer Biol. https://doi.org/10.1016/j.semcancer.2020.01.015

Eltahir HM, Fawzy MA, Mohamed EM et al (2020) Antioxidant, anti-inflammatory and anti-fibrotic effects of Boswellia serrate gum resin in CCl4-induced hepatotoxicity. Exp Ther Med 19:1313-1321. https://doi.org/10.3892/etm.2019.8353

Etzel R (1996) Special extract of Boswellia serrata (H15) in the treatment of rheumatoid arthritis. Phytomedicine 3:91-94

Fedson DS (2016) Treating the host response to emerging virus diseases: lessons learned from sepsis, pneumonia, influenza and Ebola. Ann Tran Med 4:421. https://doi.org/10.21037/atm. 2016.11.03

Ferrara T, De Vincentiis G, Di Pierro F (2015) Functional study on Boswellia phytosome as complementary intervention in asthmatic patients. Eur Rev Med Pharmacol Sci 19:3757-3762

Firenzuoli F, Antonelli M, Donelli D, Gensini GF, Maggini V (2020) Cautions and opportunities for botanicals in COVID19 patients: a comment on the position of the French Agency for Food, Environmental and Occupational Health \& Safety. J Altern Complement Med 10:851-853. https://doi.org/10.1089/ acm.2020.0266

Forouzanfar F, Hosseinzadeh H, Ebrahimzadeh Bideskan A, Sadeghnia HR (2016) Aqueous and ethanolic extracts of boswellia serrata protect against focal cerebral ischemia and reperfusion injury in rats. Phytother Res 12:1954-1967. https://doi.org/10.1002/ptr. 5701

Franić Z, Franić Z, Vrkić N, Gabaj NN, Petek I (2020) Effect of extract from Boswellia serrata gum resin on decrease of GAD65 autoantibodies in a patient with latent autoimmune diabetes in adults. Altern Ther Health Med 26:38-40

Gao J, Tian Z, Yang X (2020) Breakthrough: chloroquine phosphate has shown apparent efficacy in treatment of COVID-19 associated pneumonia in clinical studies. Biosci Trends 14:72-73. https://doi.org/10.5582/bst.2020.0104

Gautret P, Lagier JC, Parola P et al (2020) Hydroxychloroquine and azithromycin as a treatment of COVID-19: results of an openlabel nonrandomized clinical trial. Int J Antimicrob Agents. https://doi.org/10.1016/j.ijantimicag.2020.105949

Gayathri B, Manjula N, Vinaykumar KS et al (2007) Pure compound from Boswellia serrata extract exhibits anti-inflammatory property in human PBMCs and mouse macrophages through inhibition of TNFalpha, IL-1beta, NO and MAP kinases. Int Immunopharmacol 7:473-482

Gilbert NC, Gerstmeier J, Schexnaydre EE, Börner F, Garscha U, Neau DB, Werz O, Newcomer ME (2020) Structural and mechanistic insights into 5-lipoxygenase inhibition by natural products. Nat Chem Biol 16:783-790. https://doi.org/10.1038/ s41589-020-0544-7

Gohel K, Patel K, Shah P et al (2018) Box-Behnken design-assisted optimization for simultaneous estimation of quercetin, kaempferol, and keto-[beta]-boswellic acid by high-performance thinlayer chromatography method. J Planar Chromatogr Mod TLC $31: 318-325$
Gomaa AA, Abdel-Wadood YA (2021) The potential of glycyrrhizin and licorice extract in combating COVID-19 and associated conditions. Phytomed Plus. https://doi.org/10.1016/j.phyplu.2021. 100043

Gomaa AA, Makboul R, Al-Mokhtarc M et al (2019) Polyphenol-rich boswellia serrata gum prevents cognitive impairment and insulin resistance of diabetic rats through inhibition of GSK3 $\beta$ activity, oxidative stress and pro-inflammatory cytokines. Biomed Pharmacother 109:281-292

Goswami D, Mahapatra AD, Banerjee S, Kar A, Ojha D, Mukherjee PK, Chattopadhyay D (2018) Boswellia serrata oleo-gum-resin and $\beta$-boswellic acid inhibits HSV-1 infection in vitro through modulation of NF-KB and p38 MAP kinase signaling. Phytomedicine 51:94-103. https://doi.org/10.1016/j.phymed.2018.10.016

Gupta I, Gupta V, Parihar S et al (1998) Effect of Boswellia serrata gum resin in patient with bronchial asthma: results of a double blind, placebo controlled 6 week clinical study. Eur J Med Res 3:511-514

Gupta A, Khajuria A, Singh J, Singh S, Suri KA, Qazi GN (2011) Immunological adjuvant effect of Boswellia serrata (BOS 2000) on specific antibody and cellular response to ovalbumin in mice. Int Immunopharmacol 11:968-975. https://doi.org/10.1016/j. intimp.2011.02.011

Hasson SS, Al-Balushi MS, Sallam TA, Idris MA, Habbal O, Al-Jabri AA (2011) In vitro antibacterial activity of three medicinal plants-Boswellia (Luban) species. Asian Pac J Trop Biomed 1:S178-S182

Hewedy WA (2020) Effect of Boswellia serrata on rat trachea contractility in vitro. Nat Prod J 10:33-43. https://doi.org/10.2174/22103 15509666190206122050

Houssen ME, Ragab A, Mesbah A et al (2010) Natural anti-inflammatory products and leukotriene inhibitors as complementary therapy for bronchial asthma. Clin Biochem 43(10-11):887-890. https://doi.org/10.1016/j.clinbiochem.2010.04.061

Huang C, Wang Y, Li X et al (2020) Clinical features of patients infected with 2019 novel coronavirus in Wuhan. China Lancet. https://doi.org/10.1016/S0140-6736(20)30183-5

Hüsch J, Bohnet J, Fricker G, Skarke C, Artaria C, Appendino G et al (2013) Enhanced absorption of boswellic acids by a lecithin delivery form (Phytosome ${ }^{\circledR}$ ) of Boswellia extract. Fitoterapia 84:89-98. https://doi.org/10.1016/j.fitote.2012.10.002

Jiang XW, Zhang BQ, Qiao L et al (2018) Acetyl-11-keto- $\beta$-boswellic acid extracted from Boswellia serrata promotes Schwann cell proliferation and sciatic nerve function recovery. Neural Regen Res 13:484-491

Kadambari S, Klenerman P, Pollard AJ (2020) Why the elderly appear to be more severely affected by COVID-19: the potential role of immunosenescence and CMV. Rev Med Virol 30(5):e2144. https://doi.org/10.1002/rmv.2144

Kasali AA, Adio AM, Kundaya OE, Oyedeji AO, Eshilokun AO, Adefenwa M (2002) Antimicrobial activity of the essential oil of Boswellia serrata Roxb. J Essent Oil Bear Plants 5(3):173-175

Katragunta K, Siva B, Kondepudi N, Vadaparthi PR, Rama Rao N et al (2019) Estimation of boswellic acids in herbal formulations containing Boswellia serrata extract and comprehensive characterization of secondary metabolites using UPLC-Q-Tof-MSe. J Pharm Anal 9(6):414-422. https://doi.org/10.1016/j.jpha.2019. 09.007

Khajuria A, Gupta A, Suden P, Singh S, Malik F, Singh J, Gupta BD, Suri KA et al (2008) Immunmodulatoryactivity of biopolymeric fraction BOS 2000 from Boswellia serrata. Phytother Res 22:340-348

Khosravi M, Mahmoodian H, Moghadamnia A, Poorsattar A, Chitsazan M (2011) The effect of frankincense in the treatment of moderate plaque-induced gingivitis: a double blinded randomized clinical trial. Daru 19(4):288-94 
Khurana S, Singh P, Sharad N et al (2021) Profile of co-infections \& secondary infections in COVID-19 patients at a dedicated COVID-19 facility of a tertiary care Indian hospital: implication on antimicrobial resistance. Indian J Med Microbiol 39(2):147153. https://doi.org/10.1016/j.ijmmb.2020.10.014

Kim JS, Lee JY, Yang JW, Lee KH, Effenberger M, Szpirt W, Kronbichler A, Shin JI (2021) Immunopathogenesis and treatment of cytokine storm in COVID-19. Theranostics 11(1):316-329. https://doi.org/10.7150/thno.49713

Krishnaraju AV, Sundararaju D, Vamsikrishna U et al (2010) Safety and toxicological evaluation of Aflapin: a novel Boswelliaderived anti-inflammatory product. Toxicol Mech Methods 20(9):556-563. https://doi.org/10.3109/15376516.2010.497978

Lalithakumari K, Krishnaraju AV, Sengupta K et al (2006) Safety and toxicological evaluation of a novel, standardized 3-O-acetyl-11keto-beta-boswellic acid (AKBA)-enriched Boswellia serrata extract (5-Loxin $\left.{ }^{\circledR}\right)$. Toxicol Mech Methods 16(4):199-226. https://doi.org/10.1080/15376520600620232

Lewinska A, Adamczyk-Grochala J, Bloniarz D et al (2020) AMPKmediated senolytic and senostatic activity of quercetin surface functionalized $\mathrm{Fe} 3 \mathrm{O} 4$ nanoparticles during oxidant-induced senescence in human fibroblasts. Redox Biol 28:101337. https:// doi.org/10.1016/j.redox.2019.101337

Liu Z, Liu X, Sang L et al (2015) Boswellic acid attenuates asthma phenotypes by downregulation of GATA3 via pSTAT6 inhibition in a murine model of asthma. Int J Clin Exp Pathol 8(1):236-243

Loeser K, Seemann S, König S et al (2018) Protective effect of casperome R, an orally bioavailable frankincense extract, on lipopolysaccharide induced systemic inflammation in mice. Front Pharmacol 9:387. https://doi.org/10.3389/fphar.2018.00387

Luo H, Tang QL, Shang YX et al (2020) Can Chinese medicine be used for prevention of corona virus disease 2019 (COVID-19)? A review of historical classics, research evidence and current prevention programs. Chin J Integr Med 26(4):243-250. https:// doi.org/10.1007/s11655-020-3192-6

Malavolta M, Giacconi R, Brunetti D et al (2020) Exploring the relevance of senotherapeutics for the current SARS-CoV-2 emergency and similar future global health threats. Cells 9(4):909. https://doi.org/10.3390/cells9040909

Maraghehpour B, Khayamzadeh M, Najafi S, Kharazifard M (2016) Traditionally used herbal medicines with antibacterial effect on Aggegatibacter actinomycetemcomitans: Boswellia serrata and Nigella sativa. J Indian Soc Periodontol 20(6):603-607. https:// doi.org/10.4103/jisp.jisp_12_17

Marouf N, Cai W, Said KN et al (2021) Association between periodontitis and severity of COVID-19 infection: a case-control study. J Clin Periodontol. https://doi.org/10.1111/jcpe.13435

Meins J, Behnam D, Abdel-Tawab M (2018) Enhanced absorption of boswellic acids by a micellar solubilized delivery form of Boswellia extract. NFS J 11:12-16. https://doi.org/10.1016/j.nfs. 2018.04.001

Miao XD, Zheng LJ, Zhao ZZ, Su SL, Zhu Y et al (2019) Protective effect and mechanism of boswellic acid and myrrha sesquiterpenes with different proportions of compatibility on neuroinflammation by LPS-induced BV2 cells combined with network pharmacology. Molecules 24(21):3946. https://doi.org/10.3390/ molecules24213946

Mikhaeil BR, Maatooq GT, Badria FA et al (2003) Chemistry and immunomodulatory activity of frankincense oil. Z Naturforsch C J Biosci 58(3-4):230-238. https://doi.org/10.1515/ znc-2003-3-416

Muñoz-Espín D, Serrano M (2014) Cellular senescence: from physiology to pathology. Nat Rev Mol Cell Biol 15:482-496

Patel NB, Patel KC (2014) Antibacterial activity of Boswellia serrata Roxb. ex colebr ethnomedicinal plant against gram positive UTI pathogens. Life Sci Leafl 53:79-88
Pengzong Z, Yuanmin L, Xiaoming X et al (2019) Wound healing potential of the standardized extract of boswellia serrata on experimental diabetic foot ulcer via inhibition of inflammatory, angiogenetic and apoptotic markers. Planta Med 85(8):657-669. https://doi.org/10.1055/a-0881-3000

Pum A, Ennemoser M, Adage T, Kungl AJ (2021) Cytokines and chemokines in SARS-CoV-2 infections-therapeutic strategies targeting cytokine storm. Biomolecules 11(1):91. https://doi. org/10.3390/biom11010091

Pungle P, Banavalikar M, Suthar A et al (2003) Immunomodulatory activity of boswellic acids of Boswellia serrata Roxb. Indian J Exp Biol 41(12):1460-1462

Rad MZ, Taherian H (2020) Effect of mouthwash with Boswellia extract on the prevention of dental plaque formation in patients under mechanical ventilation. Nurs Midwifery Stud 9:77-82

Raja AF, Ali F, Khan IA, Shawl AS, Arora DS, Shah BA, Taneja SC (2011a) Antistaphylococcal and biofilm inhibitory activities of acetyl-11-keto- $\beta$-boswellic acid from Boswellia serrata. BMC Microbiol 11:54. https://doi.org/10.1186/1471-2180-11-54

Raja AF, Al F, Khan IA, Shawl AS, Arora DS (2011b) Acetyl-11-keto$\beta$-boswellic acid (AKBA); targeting oral cavity pathogens. BMC Res Notes 4:406. https://doi.org/10.1186/1756-0500-4-406

Rajabian A, Boroushaki MT, Hayatdavoudi P, Sadeghnia HR (2016) Boswellia serrata protects against glutamate-induced oxidative stress and apoptosis in PC12 and N2a cells. DNA Cell Biol 35(11):666-679. https://doi.org/10.1089/dna.2016.3332

Rajabian A, Sadeghnia HR, Hosseini A, Mousavi SH, Boroushaki MT (2020) 3-Acetyl-11-keto- $\beta$-boswellic acid attenuated oxidative glutamate toxicity in neuron-like cell lines by apoptosis inhibition. J Cell Biochem 121(2):1778-1789. https://doi.org/10.1002/ jcb. 29413

Rashan L, Hakkim FL, Idrees M et al (2019) Boswellia gum resin and essential oils: potential health benefits-an evidence based review. Int J Nutr Pharmacol Neurol Dis 9:53-71

Rodriguez-Garcia JL, Sanchez-Nievas G, Arevalo-Serrano J, GarciaGomez C et al (2021) Baricitinib improves respiratory function in patients treated with corticosteroids for SARS-CoV-2 pneumonia: an observational cohort study. Rheumatology (Oxford) 60(1):399-407. https://doi.org/10.1093/rheumatology/keaa587

Rothan HA, Byrareddy SN (2020) The epidemiology and pathogenesis of coronavirus disease (COVID-19) outbreak. J Autoimmun. https://doi.org/10.1016/j.jaut.2020.10243

Roy NK, Parama D, Banik K, Bordoloi D, Devi AK et al (2019) An update on pharmacological potential of boswellic acids against chronic diseases. Int J Mol Sci 20(17):4101. https://doi.org/10. 3390/ijms20174101

Sabra SM, Al-Masoudi LM (2014) The effect of using frankincense (boswellia sacra) chewing gum on the microbial contents of buccal/oral cavity, Taif, KSA. J Dent Med Sci 13(4):77-82

Sadeghnia HR, Arjmand F, Ghorbani A (2017) Neuroprotective effect of boswellia serrate and its active constituent acetyl 11-keto$\beta$-boswellic acid against oxygen-glucose serum deprivationinduced cell injury. Acta Pol Pharm 74(3):911-920

Sadhasivam S, Palanivel S, Ghosh S (2016) Synergistic antimicrobial activity of Boswellia serrata Roxb. ex Colebr. (Burseraceae) essential oil with various azoles against pathogens associated with skin, scalp and nail infections. Lett Appl Microbiol 63(6):495-501. https://doi.org/10.1111/lam.12683

Safayhi H, Rall B, Sailer ER (1997) Inhibition by boswellic acids of human leukocyte elastase. J Pharmacol Exp Ther 281(1):460-463

Schillaci D, Arizza V, Dayton T, Camarda L, Di Stefano V (2008) In vitro anti-biofilm activity of Boswellia spp. oleogum resin essential oils. Lett Appl Microbiol 47(5):433-438

Schmiech M, Lang SJ, Ulrich J, Werner K, Rashan LJ, Syrovets T, Simmet T (2019) Comparative investigation of frankincense nutraceuticals: correlation of boswellic and lupeolic acid contents with 
cytokine release inhibition and toxicity against triple-negative breast cancer cells. Nutrients 11(10):2341. https://doi.org/10. 3390/nu11102341

Schmiech M, Ulrich J, Lang SJ, Büchele B, Paetz C, St-Gelais A et al (2021) 11-Keto- $\alpha$-boswellic acid, a novel triterpenoid from Boswellia spp. with chemotaxonomic potential and antitumor activity against triple-negative breast cancer cells. Molecules 26(2):366. https://doi.org/10.3390/molecules26020366

Schrott E, Laufer S, Lämmerhofer M, Ammon HP (2014) Extract from gum resin of Boswellia serrata decreases IA(2)-antibody in a patient with "late onset autoimmune diabetes of the adult" (LADA). Phytomedicine 21(6):786. https://doi.org/10.1016/j. phymed.2014.02.004

Şehirli AÖ, Aksoy U, Koca-Ünsal RB, Sayıner S (2021) Role of NLRP3 inflammasome in COVID-19 and periodontitis: possible protective effect of melatonin. Med Hypotheses 151:110588. https://doi.org/10.1016/j.mehy.2021.110588

Seif F, Aazami H, Khoshmirsafa M, Kamali M, Mohsenzadegan M, Pornour M, Mansouri D (2020) JAK inhibition as a new treatment strategy for patients with COVID-19. Int Arch Allergy Immunol 181(6):467-475. https://doi.org/10.1159/000508247

Shang P, Liu W, Liu T et al (2016) Acetyl-11-keto- $\beta$-boswellic acid attenuates prooxidant and profibrotic mechanisms involving transforming growth factor- $\beta 1$, and improves vascular remodeling in spontaneously hypertensive rats. Sci Rep 6:39809. https:// doi.org/10.1038/srep39809

Sharma T, Jana S (2020) Investigation of molecular properties that influence the permeability and oral bioavailability of major $\beta$-boswellic acids. Eur J Drug Metab Pharmacokinet 45:243-255. https://doi.org/10.1007/s13318-019-00599-z

Sharma ML, Kaul A, Khajuria A, Singh S, Singh GB (1996) Immunomodulatory activity of boswellic acids (pentacyclic triterpene acids) from Boswellia serrata. Phytother Res 10:107-112

Sharma S, Thawani V, Hingorani L et al (2004) Pharmacokinetic study of 11-keto-b-boswellic acid. Phytomed 11:1255-1260

Si L, Meng K, Tian Z et al (2018) Triterpenoids manipulate a broad range of virus-host fusion via wrapping the HR2 domain prevalent in viral envelopes. Sci Adv 11:eaau8408. https://doi.org/10. $1126 /$ sciadv.aau 8408

Siddiqui MZ (2011) Boswellia serrata, a potential anti-inflammatory agent: an overview. Indian J Pharm Sci 73:255-261

Singh GB, Bani S, Singh S (1996) Toxicity and safety evaluation of boswellic acids. Phytomed 3:87-90

Singh S, Khajuria A, Taneja SC, Johri RK et al (2008a) Boswellic acids: a leukotriene inhibitor also effective through topical application in inflammatory disorders. Phytomedicine 15:400-407

Singh S, Khajuria A, Taneja SC, Johri RK et al (2008b) The gastric ulcer protective effect of boswellic acids, a leukotriene inhibitor from Boswellia serrata, in rats. Phytomedicine 15:408-415

Singh P, Chacko KM, Aggarwal ML et al (2012) A-90 day gavage safety assessment of Boswellia serrata in rats. Toxicol Int 19(3):273-278. https://doi.org/10.4103/0971-6580.103668

Singh AK, Singh A, Shaikh A et al (2020) Chloroquine and hydroxychloroquine in the treatment of COVID-19 with or without diabetes: a systematic search and a narrative review with a special reference to India and other developing countries. Diabetes Metab Syndr. https://doi.org/10.1016/j.dsx.2020.03.011

Song G, Liang G, Liu W (2020) Fungal co-infections associated with global covid-19 pandemic: a clinical and diagnostic perspective from China. Mycopathologia 185(4):599-606. https://doi.org/10. 1007/s11046-020-00462-9

Soni KK, Meshram D, Lawal TO et al (2020) Fractions of Boswellia serrata suppress LTA4, LTC4, cyclooxygenase-2 activities and mRNA in HL-60 cells and reduce lung inflammation in BALB/c mice. Curr Drug Discov Technol. https://doi.org/10.2174/15701 63817666200127112928
Stebbing J, Phelan A, Griffin I, Tucker C, Oechsle O, Smith D, Richardson P (2020) COVID-19: combining antiviral and anti-inflammatory treatments. Lancet Infect Dis 20:400-402

Stebbing J, Sánchez Nievas G, Falcone M, Youhanna S, Richardson $P$ et al (2021) JAK inhibition reduces SARS-CoV-2 liver infectivity and modulates inflammatory responses to reduce morbidity and mortality. Sci Adv 7(1):eabe4724. https://doi. org/10.1126/sciadv.abe4724

Stürner KH, Stellmann JP, Dörr J, Paul F, Friede T, Schammler S, Reinhardt $S$ et al (2018) A standardised frankincense extract reduces disease activity in relapsing-remitting multiple sclerosis (the SABA phase IIa trial). J Neurol Neurosurg Psychiatry 89(4):330-338. https://doi.org/10.1136/jnnp-2017-317101

Stürner KH, Werz O, Koeberle A, Otto M, Pless O, Leypoldt F, Paul F, Heesen C (2020) Lipid mediator profiles predict response to therapy with an oral frankincense extract in relapsing-remitting multiple sclerosis. Sci Rep 10(1):8776. https://doi.org/10.1038/ s41598-020-65215-6

Syrovets T, Buchele B, Krauss C, Laumonnier Y, Simmet T (2005) Acetyl-boswellic acids inhibit lipopolysaccharide-mediated TNF-alpha induction in monocytes by direct interaction with IkappaB kinase. J Immunol 174:498

Tawfik MK (2016) Anti-aggregatory effect of boswellic acid in highfat fed rats: involvement of redox and inflammatory cascades. Arch Med Sci 12(6):1354-1361. https://doi.org/10.5114/aoms. 2016.60675

Venkatesh H, Sudharshana T, Abhishek R, Thippeswamy S, Manjunath K, Mohana D (2017) Antifungal and antimycotoxigenic properties of chemically characterized essential oil of Boswellia serrata Roxb. ex Colebr. Int J Food Prop 20:18561868. https://doi.org/10.1080/10942912.2017.1354882

Vijay S, Bansal N, Rao BK, Veeraraghavan B, Rodrigues C et al (2021) Secondary infections in hospitalized COVID-19 patients: Indian experience. Infect Drug Resist 14:1893-1903. https://doi.org/10.2147/IDR.S299774

Vijayarani KR, Govindarajulu M, Ramesh S, Alturki M, Majrashi $M$ et al (2020) Enhanced bioavailability of boswellic acid by Piper longum: a computational and pharmacokinetic study. Front Pharmacol 11:551911. https://doi.org/10.3389/fphar. 2020.551911

Von Rhein C, Weidner T, Henß L et al (2016) Curcumin and Boswellia serrata gum resin extract inhibit chikungunya and vesicular stomatitis virus infections in vitro. Antiviral Res 125:51-57. https:// doi.org/10.1016/j.antiviral.2015.11.007

Wan Y, Shang J, Graham R et al (2020) Receptor recognition by novel coronavirus from Wuhan: an analysis based on decade-long structural studies of SARS. J Virol. https://doi.org/10.1128/JVI. 00127-20

Wu D, Yang XO (2020) TH17 responses in cytokine storm of COVID19: an emerging target of JAK2 inhibitor fedratinib. J Microbiol Immunol Infect 53(3):368-370. https://doi.org/10.1016/j.jmii. 2020.03.005

Xiao S, Tian Z, Wang Y et al (2018) Recent progress in the antiviral activity and mechanism study of pentacyclic triterpenoids and their derivatives. Med Res Rev 38(3):951-976. https://doi.org/ 10.1002/med.21484

Xu M, Pirtskhalava T, Farr JN et al (2018) Senolytics improve physical function and increase lifespan in old age. Nat Med 24:1246-1256

Xu Z, Shi L, Wang Y et al (2020) Pathological findings of COVID-19 associated with acute respiratory distress syndrome. Lancet Resp Med. https://doi.org/10.1016/S2213-2600(20)30076-X

Yanez ND, Weiss NS, Romand JA et al (2020) COVID-19 mortality risk for older men and women. BMC Public Health 20:1742. https://doi.org/10.1186/s12889-020-09826-8

Yang Y, Islam MS, Wang J et al (2020) Traditional Chinese medicine in the treatment of patients infected with 2019-new 
coronavirus (SARS-CoV-2): a review and perspective. Int J Biol Sci 16(10):1708-1717. https://doi.org/10.7150/ijbs.45538

Yu G, Xiang W, Zhang T et al (2020) Effectiveness of Boswellia and Boswellia extract for osteoarthritis patients: a systematic review and meta-analysis. BMC Complement Med Ther 20:225. https:// doi.org/10.1186/s12906-020-02985-6

Zakaryan H, Arabyan E, Zandi K (2017) Flavonoids: promising natural compounds against viral infections. Arch Virol 162(9):25392551. https://doi.org/10.1007/s00705-017-3417-y

Zhang Y, Yu Y, Tian H et al (2019) Evaluation of anti-inflammatory activities of a triterpene $\beta$-elemonic acid in frankincense in vivo and in vitro. Molecules 24:1187

Zhang X, Zhang Y, Qiao W, Zhang J, Qi Z (2020) Baricitinib, a drug with potential effect to prevent SARS-COV-2 from entering target cells and control cytokine storm induced by COVID-19. Int
Immunopharmacol 86:106749. https://doi.org/10.1016/j.intimp. 2020.106749

Zhou X, Cai JG, Zhu WW et al (2015) Boswellic acid attenuates asthma phenotype by downregulation of GATA3 via nhibition of PSTAT6. Genet Mol Res 14:7463-7468

Zimmermann-Klemd AM, Reinhardt JK, Nilsu T et al (2020) Boswellia carteri extract and 3-O-acetyl-alpha-boswellic acid suppress $\mathrm{T}$ cell function. Fitoterapia 146:104694. https://doi.org/10. 1016/j.fitote.2020.104694

Publisher's Note Springer Nature remains neutral with regard to jurisdictional claims in published maps and institutional affiliations. 